\title{
Detection of intestinal parasites on field-grown strawberries in the Federal District of Brazil
}

\author{
Sandra Regina Morais da Silva ${ }^{[1]}$, Iriani Rodrigues Maldonade ${ }^{[2]}$, Verônica Cortez Ginani ${ }^{[3],}$ \\ Sônia Alves Lima ${ }^{[4]}$, Vinícios Silveira Mendes ${ }^{[1]}$, Maria Lidiane Ximendes Azevedo ${ }^{[1]}$, \\ Rodrigo Gurgel-Gonçalves ${ }^{[3]}$ and Eleuza Rodrigues Machado ${ }^{[1],[3]}$
}

[1]. Faculdade Anhanguera de Brasília, Unidade de Taguatinga, Brasília, DF. [2]. Laboratório de Ciência de Alimentos, Empresa Brasileira de Pesquisa Agropecuária (Embrapa) Hortaliças, Brasília, DF. [3]. Laboratório de Parasitologia Médica e Biologia de Vetores, Faculdade de Medicina, Universidade de Brasília, Brasília, DF. [4]. Empresa de Assistência Técnica e Extensão Rural, Brasília, DF.

\begin{abstract}
Introduction: This study evaluated the presence of pathogenic human parasites on field-grown strawberries in the Federal District of Brazil. Methods: A total of 48 samples of strawberries and 48 soil samples from 16 properties were analyzed. Results: Contaminated strawberries were detected in $56 \%$ of the properties. Schistosoma mansoni, Ascaris lumbricoides or Ascaris suum, Balantidium coli, Endolimax nana, and Entamoeba spp. were detected. Soil was contaminated with Entamoeba spp., Entamoeba coli, Strongyloides spp., Ancylostomatidae, and Hymenolepis nana. Conclusions: Producers should be instructed on the safe handling of strawberries in order to reduce the incidence of strawberries that are contaminated with enteroparasites.
\end{abstract}

Keywords: Enteroparasites. Strawberries. Transmission.

Fruits and vegetables provide important nutritional value for humans, but when they are consumed raw and without being peeled, they may transmit human pathogens. Evaluating the pathogen load of fresh produce is of great importance for public health because it indicates the hygienic conditions during production, storage, transport, and handling ${ }^{1}$.

Ascaris lumbricoides, Entamoeba coli, Entamoeba histolytica, Endolimax nana, and Giardia lamblia have been found on strawberries (Fragaria ananassa Duch) in $\mathrm{Mexico}^{2}$. In Costa Rica, microsporidia were detected on strawberries ${ }^{3}$, and in Norway, $20 \%$ of strawberries were contaminated with $G$. lamblia cysts ${ }^{4}$. Strawberries in Turkey were heavily contaminated with Enterobius vermicularis ${ }^{5}$. Salmonella, Escherichia coli ${ }^{6}$, noravirus, rotavirus, swine hepatitis E virus ${ }^{7}$, and hepatitis $\mathrm{A}$ virus ${ }^{8}$ have also been detected in strawberries in North America.

In Brazil, the cultivation of strawberries has increased in recent years. However, the contamination of Brazilian strawberries by protozoa and helminthes that pose a risk to public health has not been investigated. The Brazlândia Administrative Region of the Federal District of Brazil (FD)

\footnotetext{
Address to: Dra. Eleuza Rodrigues Machado. Laboratório de Parasitologia Médica e Biologia de Vetores/Área Patologia/FM/UnB. Caixa Postal 4569. Campus Universitário Darcy Ribeiro, Asa Norte, 70904-970 Brasília, DF, Brasil. Phone: 5561 3107-1787

e-mail: eleuzarodriguesmachado498@gmail.com

Received 22 February 2014

Accepted 5 June 2014
}

is the largest production center of strawberries in the CentralWest Region of Brazil. Strawberries produced there are sold in the FD and are also exported to the States of Bahia, Goiás, Pará, and Amazonas. As strawberries can carry pathogenic organisms, the aim of this study was to evaluate the presence of pathogenic human parasites on field-grown strawberries in FD, Brazil.

Samples of field-grown strawberries were collected in the rural area of Brazlândia, FD. Brazlândia has approximately 54,000 inhabitants. It has a total area of $474.83 \mathrm{~km}^{2}$ and is $45 \mathrm{~km}$ from Brasília $\left(15^{\circ} 47^{\prime} 56^{\prime \prime} \mathrm{S}, 47^{\circ} 52^{\prime} 0^{\prime \prime} \mathrm{W}\right)$. The region includes 1,446 hectares of vegetables and fruit, of which 141 hectares produce approximately 4,700 tons of strawberries annually; they are the most commonly cultivated fruits in Brazlândia [Empresa de Assistência Técnica e Extensão Rural (EMATER)/DF].

The producers included in this study were selected using registration data from EMATER. Data were collected from 16 out of 38 registered strawberry producers, during visits that occurred from June to September, 2013. We selected the largest producers in the region. In each selected property, three samples of 20-22 strawberries were collected manually. Each sample weighed approximately $0.2 \mathrm{~kg}$. These fruits were packed in clean plastic bags, labeled, and stored in coolers at $4^{\circ} \mathrm{C}$ until examination.

The strawberries were washed using one of two methods. The first washing method required a clean glass bowl, brushes, and tweezers. Each strawberry was handled with the tweezers and washed with a brush and distilled water. In total, each sample (20-22 strawberries) was washed with $300 \mathrm{~mL}$ of distilled water. The used water was then placed in a conical flask to allow sediment to settle for $24 \mathrm{~h}^{9}$. 
In the second washing method, the pre-washed strawberries (which had already been washed using the first method) were placed in a transparent plastic bag containing $300 \mathrm{~mL}$ of distilled water and $30 \mathrm{~mL}$ of neutral detergent $\left(\mathrm{Uselimp}^{\mathrm{TM}}\right)$. The contents of the bags were stirred and left to stand, with a gentle stirring every 20 minutes, for $1 \mathrm{~h}$ at room temperature. After $1 \mathrm{~h}$, the strawberries were removed from the bags and the used water was deposited into the conical sedimentation flask for $24 \mathrm{~h}^{9}$.

The sediments of the three samples (20-22 strawberries) from each property were recovered and constituted approximately $2 \mathrm{~mL}$ of content, which was stained by Lugol and examined until depletion using a microscope (Olympus BX 41) at 200x to $400 \mathrm{x}$ magnification. Each strawberry sample generated six slides that were analyzed under the microscope. The protozoa and helminthes that were detected were identified, measured using an ocular micrometer, and photographed using a digital camera (Sony ${ }^{\mathrm{TM}}$ Cyber-shot 5.1Mp) attached to the microscope.

Soil samples were also taken from the surface layer of soil, to a depth of approximately $3 \mathrm{~cm}$, at three sampling sites in the strawberry field of each property. The samples, which were about $0.3 \mathrm{~kg}$ each, were placed in clean plastic bags, labeled, and transported to the laboratory, where they were analyzed using two parasitological methods, Hoffmann et al. ${ }^{9}$ and Willis ${ }^{10}$. The parasitological diagnostic procedure was the same as that described for the strawberries.

Contaminants were detected in samples from nine (56\%) of the 16 properties. Schistosoma mansoni (egg), Ascaris
lumbricoides/Ascaris suum (egg), Balantidium coli (trophozoite), Entamoeba coli, Entamoeba hartmanni, Endolimax nana, and Entamoeba spp. (cysts) were detected, in addition to free-living amoebae and unidentified nematodes and mites (Figure 1). More strawberries were contaminated by protozoa than helminthes (Table 1). The first strawberry washing method was insufficient to remove parasites; A. lumbricoides and E. nana were detected after the second washing method (Table 1).

Soil samples from 13 (81\%) properties were contaminated with protozoa and helminthes, mostly identified from the sedimentationconcentration method of Hoffmann et al. ${ }^{9}$ (Table 1). Hymenolepis nana, Strongyloides spp., Ancylostomatidae, and Entamoeba spp. were found in soil samples (Figure 2).

Both soil and strawberries from eight properties were positive for helminthes, protozoa, or mites. However, some properties yielded positive results for soil samples and negative results from strawberries samples, or vice versa; for example, H. nana, Strongyloides spp., and Ancylostomatidae were detected only in soil samples (Table 1).

The results indicate that inappropriate sanitization of the strawberries can favor human infection by intestinal parasites in the FD and in other states that consume strawberries produced by this region.

Amoebae (Entamoeba spp.) were the most frequently found protozoan on the strawberries analyzed. The high frequency of Entamoeba spp. in the samples analyzed may be explained by the properties' failure to follow Good Agricultural Practices (GAP)
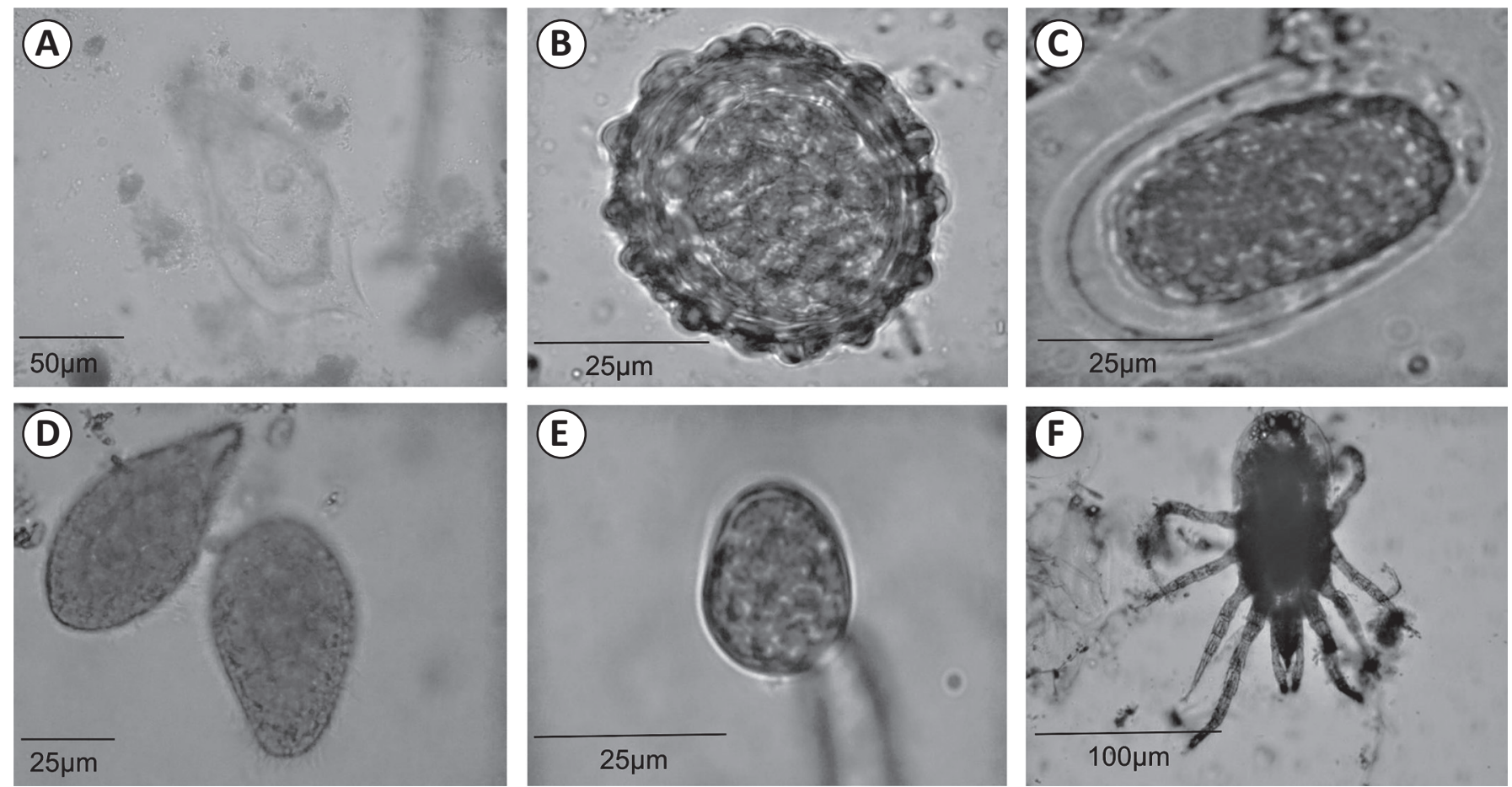

FIGURE 1 - Helminthes, protozoan, and mites detected on field-grown strawberries in the Federal District of Brazil. A: Schistosoma mansoni egg; B: Ascaris lumbricoides/Ascaris suum egg; C: Unidentified nematode egg; D: Balantidium coli; E: Entamoeba coli cyst; F: Unidentified mite. 
TABLE 1 - Occurrence of helminthes, protozoa, and mites on field-grown strawberries and soil samples, Brazlândia, Federal District, Brazil, 2013.

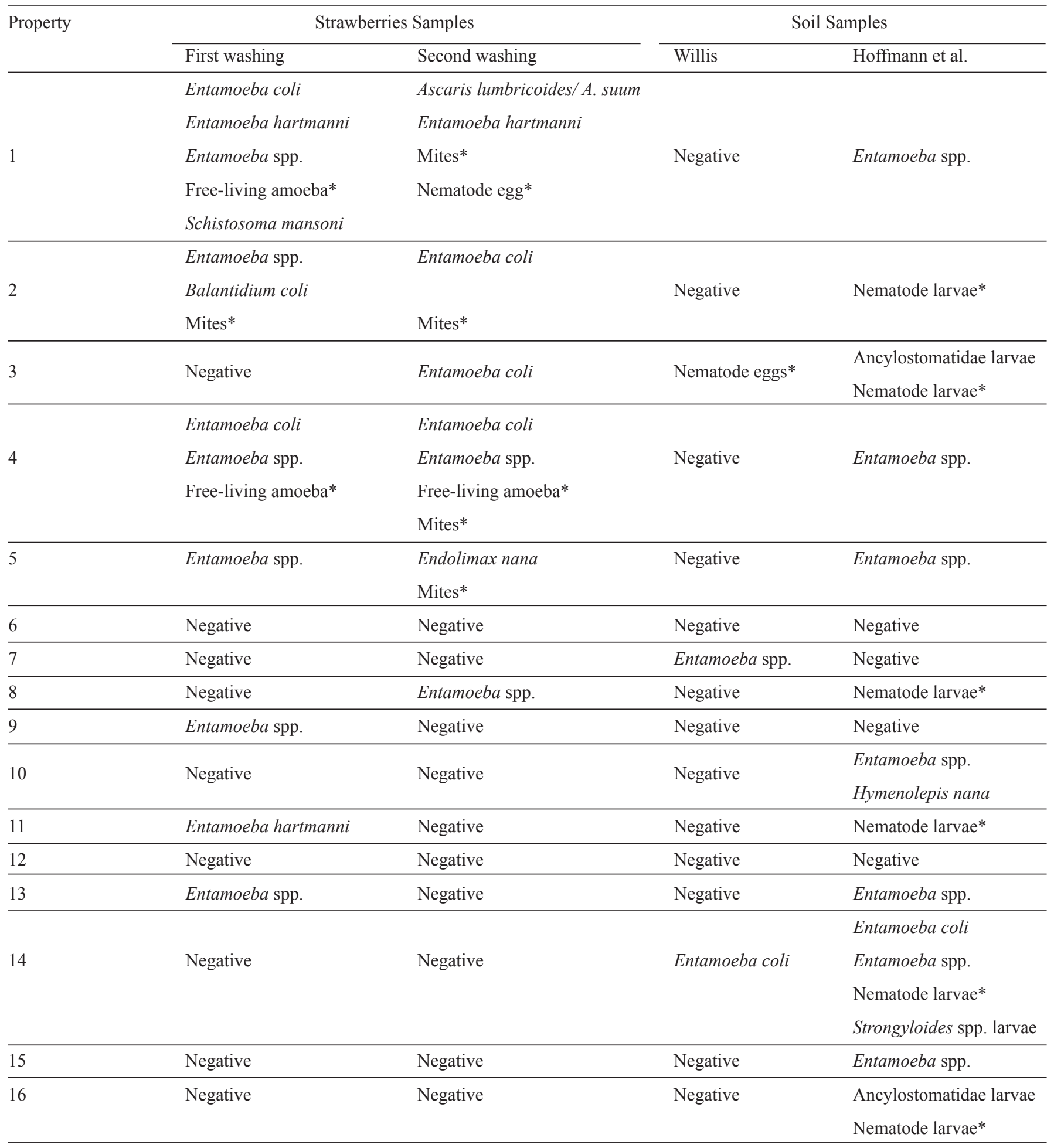

*Unidentified. 

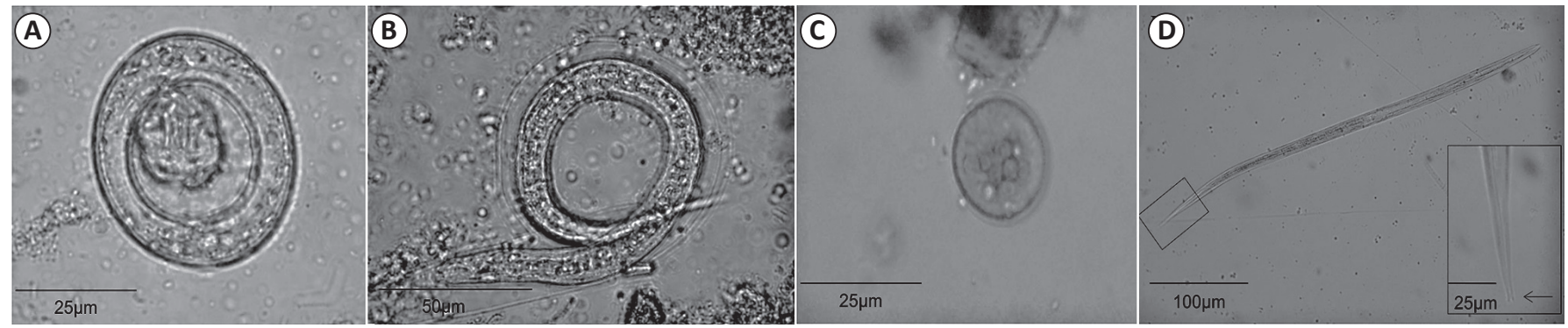

FIGURE 2 - Helminthes and protozoan detected on soil samples in the Federal District of Brazil. A: Hymenolepis nana egg; B: Ancylostomatidae larvae; C: Entamoeba coli cyst; D: Strongyloides spp. (arrow indicates the detail of the larvae tail).

during cultivation, when field-grown strawberries come in contact with soil and water that is contaminated with human and animal feces. Amoebae remained on the fruit surface after the first washing was complete, suggesting that they were strongly adhered. The mechanisms of amoebae adhesion to strawberries and other fruits and vegetables should be analyzed in future studies ${ }^{1}$.

Balantidium coli is transmitted by contact with pigs at the locations where they are bred and in slaughterhouses. Humans are infected when they ingest the cysts in food or water that is contaminated by feces from humans or animals that host the parasite, a scenario that may be occurring in Brazlândia, FD.

The presence of Ascaris lumbricoides/Ascaris suum may be related to the morphology of the eggs, which are able to adhere to fruits, and to its resistance to unfavorable environmental conditions, facilitating its survival and spread. Ascaris lumbricoides have also been detected in strawberries in Mexico' ${ }^{2}$. This is the first report of A. lumbricoides/A. suum in strawberries in Brazil.

Schistosoma mansoni eggs found on the strawberries would not infect humans; however, their presence is relevant, as it indicates that their hosts are present in the area. Although cases of autochthonous schistosomiasis and records of infection by Biomphalaria glabrata in aquatic environments have been reported in $\mathrm{FD}^{11}$, only a few cases of schistosomiasis have been detected during the last few years in this region.

The contamination of strawberries may occur due to 1) insufficient hygiene among the strawberry handlers; 2 ) contact between the strawberry and contaminated soil, 3) irrigation with contaminated water, or 4) cross-contamination after harvest during storage. In this study, the strawberries were collected according to the GAP procedures: technicians wore gloves while harvesting the fruits and placed them in sterile plastic bags in order to avoid cross-contamination. Our results suggest that contact with the soil is a likely route of contamination, because the soil is a favorable environment for the helminthes. Therefore, strawberry contact with the ground, a common situation during conventional cultivation, likely promotes contamination.

To prevent the transmission of intestinal parasites to consumers, vegetables and fruits should first be cleaned by washing. Washing in running water of good quality can reduce the microbial load, but by itself it is not sufficient to reduce contamination to a safe level. In our study, the first strawberry washing was not enough to remove all parasites (Table 1).
In addition, conventional sanitizers have been shown to have limited efficacy at removing spoilage and pathogenic microbes from the strawberry surface ${ }^{12}$.

It is important to consider that the morphological structure of the strawberries might hamper their capacity to be sanitized. Moreover, fresh produce and fruits, such as strawberries, are very perishable and highly vulnerable to microbial attacks. As conventional methods of decontamination are not effective, it is necessary to evaluate novel technologies. Pulsed ultraviolet light has the potential to be used to decontaminate raspberries and strawberries ${ }^{13}$. Furthermore, Luksiene and Paskeviciute ${ }^{14}$ showed that photosensitization may be an effective, nonthermal, and environmentally friendly microbial decontamination technique. This method can extend the shelf life of strawberries without any negative impact on antioxidant activity, amounts of phenols and anthocyanins, or color. Yoon et al. ${ }^{15}$ suggest that food safety practices in strawberry greenhouses and packaging centers should be improved, and their suggestions may be useful in the establishment of a good agricultural practice system for strawberry production.

Parasitological assessment of the quality of water used for strawberry irrigation should be performed in order to clarify the source of contamination. Further studies evaluating bacterial contamination ${ }^{6}$ are needed to understand the role of strawberries in spreading pathogens in Brazil.

The results of this survey show that a considerable number of strawberry samples are contaminated by enteroparasites, suggesting that it is necessary to conduct ongoing education for strawberry producers and harvesters, as well as providing guidance to ensure that good practices are followed. The consumer population should also be alerted to the risks of consuming strawberries that have not been properly washed and sanitized.

\section{ACKNOWLEDGMENTS}

We thank the Empresa de Assistência Técnica e Extensão Rural (EMATER) employees for their dedication in organizing and scheduling the harvesting of the strawberries and collection of soil samples from the properties of producers. We also thank Dr. Andrey Andrade (Universidade de Brasilia) for reviewing the manuscript. 


\section{REFERENCES}

1. Berger CN, Sodha SV, Shaw RK, Griffin PM, Pink D, Hand P, et al. Fresh fruit and vegetables as vehicles for the transmission of human pathogens. Environ Microbiol 2010; 12:2385-2397.

2. Spíndola Félix N, Rojas Wastavino G, de Haro Arteaga I, Cabrera Bravo M, Salazar Schettino PM. Parasite search in strawberries from Irapuato, Guanajuato and Zamora, Michoacan (Mexico). Arch Med Res 1996; 27:229-231.

3. Calvo M, Carazo M, Arias ML, Chaves C, Monge R, Chinchilla M. Prevalence of Cyclospora sp., Cryptosporidium sp., Microsporidia and fecal coliform determination in fresh fruit and vegetables consumed in Costa Rica. Arch Latinoam Nutr 2004; 54:428-432.

4. Robertson LJ, Gjerde B. Occurrence of parasites on fruits and vegetables in Norway. J Food Prot 2001; 64:1793-1798.

5. Erdogrul Ö, Şener H. The contamination of various fruit and vegetable with Enterobius vermicularis, Ascaris eggs, Entamoeba histolytica cysts and Giardia cysts. Food Control 2005; 16:557-560.

6. Knudsen DM, Yamamoto SA, Harris LJ. Survival of Salmonella spp. and Escherichia coli $\mathrm{O} 157: \mathrm{H} 7$ on fresh and frozen strawberries. J Food Prot 2001; 64:1438-1488.

7. Brassard J, Gagné MJ, Généreux M, Côté C. Detection of human food-borne and zoonotic viruses on irrigated, field-grown strawberries. Appl Environ Microbiol 2012; 78:3763-3766.
8. Niu MT, Polish LB, Robertson BH, Khanna BK, Woodruff BA, Shapiro CN, et al. Multistate outbreak of hepatitis A associated with frozen strawberries. J Infect Dis 1992; 166:518-524.

9. Hoffmann WA, Pons JA, Janer JL. The sedimentation - concentration method in Schistosomiasis mansoni. Am J Public Health 1934; 9:281-298.

10. Willis II. A simple method for de detection of hookworm ova. Med J Aust 1921; 8:375-376.

11. Barbosa FS, Coimbra Junior CEA. Esquistossomose mansônica autóctone no Distrito Federal, Brasil. Rev Saude Publica 1979; 13:108-112.

12. Yuk H, Bartz J, Schneider K. The effectiveness of sanitizer treatment in inactivation of Salmonella spp. from bell pepper, cucumber, and strawberry. J Food Sci 2006; 71:95-99.

13. Bialka KL, Demirci A. Efficacy of pulsed UV-light for the decontamination of Escherichia coli O157:H7 and Salmonella spp. on raspberries and strawberries. J Food Sci 2008; 73:201-207.

14. Luksiene Z, Paskeviciute E. Novel approach to the microbial decontamination of strawberries: chlorophyllin-based photosensitization. J Appl Microbiol 2011; 110:1274-1283.

15. Yoon Y, Kim K, Nam M, Shim WB, Ryu JG, Kim DH, et al. Microbiological assessment in strawberry production and recommendations to establish a good agricultural practice system. Foodborne Pathog Dis 2010; 7:1511-1519. 